\title{
Exploration and Practice of Mixed Teaching Based on MOOC+SPOC
}

\author{
Xinfeng Yang \\ School of Computer and Information Engineering, Nanyang Institute of Technology, Nanyang, \\ China
}

1832370485@qq.com

\section{Keywords: MOOC; SPOC; Flipped Classroom; Mixed Teaching}

\begin{abstract}
On the road of exploring the innovation of teaching mode, the new and old teaching mode are crossed, and the MOOC and SPOC are mixed with the flipped classroom model to construct a mixed teaching model based on "MOOC + SPOC + flipped classroom", make it localized and campus. In view of the small scale of specific courses to be explored, promote the innovation of teaching mode and the development of curriculum construction.
\end{abstract}

\section{Introduction}

With the ever-changing science and technology, network connectivity has always been throughout the global education process [1-2]. Based on this, more and more teaching mode has gradually entered the people's vision, for all levels of education and teaching to provide guidance and reference. The time of Flipped classroom model into our university is relatively early, in the field of application is in a wide range of disciplines, teaching activities are also relatively mature. MOOC teaching mode breaks the teaching time and space, respected by the majority of teachers in the university [3-5]. SPOC appears to be slightly unfamiliar, this localization of small-scale MOOC form has gradually entered the campus, and more and more teachers and students to accept.

On the road of exploring the innovation of teaching mode, the new and old teaching mode are crossed, and the MOOC and SPOC are mixed with the flipped classroom model to construct a mixed teaching model based on "MOOC + SPOC + flipped classroom", make it localized and campus [6-7]. In view of the small scale of specific courses to be explored, promote the innovation of teaching mode and the development of curriculum construction [8].

\section{Research on Mixed Teaching Mode}

MOOC (Massive Open Online Courses) is an online course open model that emerged in recent years [9]. MOOC courses integrate a variety of social networking tools and various forms of digital resources; form a wide range of learning tools and rich curriculum resources. MOOC courses break through the traditional curriculum time, space constraints, relying on the Internet around the world of learners at home and abroad can learn well-known university courses. MOOC courses break through the limits of traditional courses, to meet the large-scale course learners learn. MOOC course has a high enrollment rate, but also has a high dropout rate, which requires learners with strong self-learning ability to complete the course content on time.

The concept of SPOC (Small Private Online Course) was first proposed and used by Professor Fox of the University of California at Berkeley [10]. Small and Private is relative to the Massive and Open in MOOC, Small refers to the size of students in general to dozens of people to hundreds of people, Private refers to the students to set restrictive access conditions, to meet the requirements of the applicant can be included SPOC course. The current SPOC teaching case is a combination of classroom teaching and online teaching mixed learning model, using MOOC lectures video (or at the same time using its online evaluation and other functions), implement flipped classroom teaching. The basic process is that teachers put these video materials as homework assignments to students, and then in the physical classroom teaching to answer student questions, to understand the students have absorbed what knowledge, which has not been absorbed in the class with students to deal with homework Or other tasks. In general, teachers can freely set and control the progress, 
rhythm and scoring system of the course according to their preferences and the needs of the students.

Flipped Classroom refers to adjust the time inside and outside the classroom, transfer the decision from the teacher to the students. In this teaching model, the valuable time in the classroom, students can focus more on the initiative of project-based learning, joint research to solve the localization or globalization challenges and other real world problems, so as to obtain a deeper understanding. Teachers do not take up the classroom time to teach information, the information needs students to complete self-study before class, they can watch video lectures, podcasts, reading enhanced e-books, but also on the network with other students to discuss At any time to access the required materials. Teachers can also have more time to communicate with everyone. After the course, students plan their own learning content, learn rhythm, style and presentation of knowledge. Teachers use lecture and co-ordination to meet the needs of students and promote their individual learning. The goal is to enable students to obtain more real learning.

\section{Reform and Practice of Mixed Teaching Mode}

\section{Construction of SPOC Resources}

SPOC is synchronized and asynchronous two ways, synchronous SPOC is completely follow a course of starting MOOC source to learning, teachers can only add content, cannot modify the original content of the source course; asynchronous SPOC is a copy of the source course term content, teachers can delete the contents of the original MOOC, but also to add content. SPOC course is divided into upper and lower parts, the upper part is shared MOOC course content, and in the lower part the teacher can upload and follow the MOOC different teaching content. In the spring of 2017, we opened the SPOC course designed by C language program in Chinese university MOOC. The course was synchronized with Professor Li Fengxia's MOOC course designed by $\mathrm{C}$ language program.

\section{Implementation of flipped Classroom Program}

The reform is based on the basic knowledge of $\mathrm{C}$ language, suitable for online MOOC study, and the experimental content suitable for line tasks, activities, groups, discussions and other forms, in accordance with the teaching mode of the curriculum to carry out classroom activities.

To achieve the teaching effect of flipped classroom, on the one hand, students need to have sufficient knowledge reserves, so as to make the knowledge from passive acceptance into active recognition and independent output, so as to support the interaction with teachers; on the other hand, teachers need to teach content carefully designed and arranged. Therefore, the flipped classroom teaching method is not suitable for the whole course, only suitable for part of the contents of some chapters and only suitable for classroom teaching as part of the use.

\section{Use QQ and We Chat as a Teaching aid}

As the universal use of QQ and WeChat, you can use QQ and WeChat as a teaching aid, for the release of teaching advice, assignments and questions Q \& A. Gradual information release can stimulate students to step into the ladder thinking, online and offline flipped classroom teaching mode to provide an effective way.

(1) Pre-class: the unit test content was published to the course QQ group or WeChat group, the students use the phone to read the test questions, the answer directly was written on paper; in the course group teachers published the answer, and take the way of students' assessment to assessment papers.

(2) In-class: Teachers can publish experimental questions, experimental requirements, problem description, problem analysis, algorithm design, prompt code and program code from time to time in the course group according to the degree of difficulty in the experiment and the degree of reaction in the student class. Students will answer the question or answer the first time to the group, teachers Q \& A, students share learning each other.

(3) After school: students uploaded the work which was not completed on the machine including the source code which was not passed on the compiler to the course group, students and teachers can help jointly debug, by adding points, red envelopes, written reviews, etc. to encourage. 


\section{Implementation Effect and Evaluation}

\section{Comparison of Online and Offline Results}

We randomly selected a class of 50 students from the computer science and technology to form experimental classes, use mixed teaching and flipped classroom teaching mode, for the same professional two other ordinary class using the traditional model.

Online MOOC results are weighted by unit testing, operations, discussion and final test results, and the number of ultimately made MOOC effective results is 48 , of which 17 were outstanding, qualified 27, failed 4 people, respectively, accounting for $35.42 \%, 56.25 \%$ and $8.33 \%$ of the total. Beijing Institute of Technology opened the total number of MOOC learning is 8103 people, of which 2927 outstanding, 2552 people qualified, 2624 people failed, and accounting for $36.1 \%, 31.5 \%$ and $32.4 \%$ of the total number of elective courses respectively. Higher retreat rate is a common phenomenon of MOOC, but my school's excellent rate is fair to MOOC overall flat, the pass rate is much higher than the overall level of MOOC, indicating that the overall level of students higher than MOOC teaching requirements.

The results of the line comparison data is from a teacher at the same time teaching ordinary classes and experimental classes. We compare from the highest score, the lowest score and the average score 3, as shown in Table 1, we can see that the highest class performance, the lowest score and average scores are higher than the ordinary class, indicating that the mixed teaching model to improve the course Completion rate and excellent rate.

Table 1 Comparison of course scores from Ordinary classes and experimental classes

\begin{tabular}{cccc}
\hline Course class & Highest score & Lowest score & Average score \\
\hline Experimental class & 98 & 55 & 78 \\
Ordinary class & 95 & 48 & 72 \\
\hline
\end{tabular}

\section{Investigation and Evaluation}

We conducted a questionnaire survey on MOOC + SPOC platform, resource use, mixed teaching, flip classroom, paperless examination and so on. The results showed that students were satisfied with the online teaching and flipping classroom teaching mode.

\section{Summary}

The establishment of a new teaching model not only can guide the teaching theory, but also be used as a reference for teaching practice. Colleges and universities can exchange and summarize the MOOC + SPOC teaching model reform experience, and gradually form a new, mature teaching model and to promote. Through the preliminary exploration of the mixed teaching model of MOOC + SPOC, the teacher's teaching idea is updated, the teaching skill of the teachers is improved, and the students are allowed to experience the new teaching mode. We should also explore the new model of MOOC + SPOC teaching and learning, improve the students' practical ability, improve the quality and level of personnel training, the courage to explore and practice.

\section{Acknowledgement}

The author is grateful to the support of 2017 Nanyang Institute of Technology Education and Teaching Reform Research Project.

\section{References}

[1] D.C. Zhan, L.S. Nie, L.J. Zhang. China University Teaching, (2015) No.8, p.29.

[2] F.X. Li, Y.F. Chen, Y. Yu. Computer Education, (2016) No.1, p.17.

[3] D.C. Zhan. Computer Education, (2016) No.1, p.12.

[4] Y.Q. Zhou, S.Y. Wan. China Education Info, (2016) No.2, p.10.

[5] L.Q. Yang. Education Modernization, (2016) No.3, p.234.

[6] M.X. Zeng, G.P. Li. China Educational Technology, (2015) No.11, p.28. 
[7] B. He, Y. Cao. China Educational Technology, (2015) No.3, p.22.

[8] Y.J. Guo. Journal of Higher Education Management, (2014) No.5, p.22.

[9] X.H. Su, L.L. Zhao, T.T. Wang. Computer Education, (2014) No.3, p.36.

[10] T.T. Wang, X.H. Su, P.J. Ma, Y.Y. Wang. Computers \& Education, (2011) No.1, p.220. 